\title{
Pengujian Gugus Fungsi Silika Berbasis Sekam Padi Dengan Variasi Suhu \& Konsentrasi Cetyltrimethylammonium Bromide Sebagai Bahan Baku Mesoporous Silica
}

\author{
Leni Rumiyanti $^{(1)()^{*}}$, Catur Destiana ${ }^{(\mathrm{b})}$, Ria Oktaviani ${ }^{(\mathrm{c})}$, \\ Simon Sembiring ${ }^{(\mathrm{d})}$, Syafriadi ${ }^{(\mathrm{e})}$, dan Ni Luh Gede Ratna Juliasih ${ }^{(2)(\mathrm{f})}$ \\ (1) Jurusan Fisika, FMIPA, Universitas Lampung, Bandar Lampung, Indonesia 35141 \\ (2) Jurusan Kimia, FMIPA, Universitas Lampung, Bandar Lampung, Indonesia 35141 \\ (a)lenirumiyanti.@fmipa.unila.ac.id, ${ }^{(b)}$ caturdestiana1998@gmail.com, ${ }^{(c)}$ riaoktaviani045@gmail.com, \\ ${ }^{(d)}$ simonsembiring2@gmail.com, ${ }^{(e)}$ syafriadi.1961@fmipa.unila.ac.id, \\ (f)niluhratna.juliasih@fmipa.unila.ac.id
}

Diterima (3 Februari 2021), Direvisi (30 Juni 2021)

\begin{abstract}
Research has been conducted to test silica function groups based on rice husks with temperature variations and concentrations of Cetyltrimethylammonium Bromide as raw materials for mesoporous silica. In this study, rice husk silica was synthesized by alkaline method with variations in CTAB concentrations of $2.0 \%, 2.5 \%, 3.0 \%, 3.5 \%$ and hydrothermal treatments with temperature variations of $120,130,145$, and $160^{\circ} \mathrm{C}$ for 1 hour in an autoclave. Fourier-Transform Infrared (FTIR) results showed the presence of the most dominant clusters, namely $\mathrm{Si}-\mathrm{O}$-Si and other groups such as $\mathrm{C}-\mathrm{H},-\mathrm{H}, \mathrm{O}-\mathrm{H}$, and $-\mathrm{OH}$. Therefore, silica-based rice husks can be used as raw materials mesoporous silica.
\end{abstract}

Keywords: Cetyltrimethylammonium Bromide, function group, rice husk, mesoporous silica, temperature

\begin{abstract}
Abstrak Telah dilakukan penelitian mengenai pengujian gugus fungsi silika berbasis sekam padi dengan variasi suhu dan konsentrasi Cetyltrimethylammonium Bromide sebagai bahan baku mesoporous silica.. Pada penelitian ini, silika sekam padi disintesis dengan metode alkalis dengan variasi konsentrasi CTAB sebesar $2.0 \%, 2.5 \%, 3.0 \%, 3.5 \%$ dan perlakuan hidrotermal dengan variasi suhu $120,130,145$, dan $160^{\circ} \mathrm{C}$ selama 1 jam dalam autoclave. Hasil Fourier-Transform Infrared (FTIR) menunjukkan adanya gugus yang paling dominan, yaitu Si-O-Si dan gugus lain seperti C-H, -H, O-H, dan -OH. Oleh karena itu, silika berbasis sekam padi dapat digunakan sebagai bahan baku mesoporous silica.
\end{abstract}

Kata kunci: Cetyltrimethylammonium Bromide, gugus fungsi, sekam padi, mesoporous silica, suhu 


\section{PENDAHULUAN}

Meningkatnya kebutuhan bahan yang digunakan dalam membuat produk, yakni bahan baku (raw materials) dalam sebuah industri adalah salah satu konsekuensi logis dari Revolusi Industrialisasi 4.0. Namun, di sisi lain kebutuhan bahan baku tersebut tidak mampu lagi dipenuhi oleh sumber yang umum dimanfaatkan. Sangatlah penting untuk mendapatkan bahan baku terbarukan (renewable materials) yang berasal dari sumber yang dapat terus beregenerasi, contohnya berasal dari tumbuhan, binatang atau ekosistem sehingga produksinya dapat dilakukan berulang kali.

Salah satu renewable materials yang dapat digunakan sebagai bahan baku Mesoporous Silica adalah sekam padi yang jumlahnya melimpah di Indonesia tetapi pemanfaatannya belum maksimal. Menurut Badan Pusat Statistik (BPS), produksi padi di Provinsi Lampung periode Januari-Desember 2018 mencapai $\pm 1,90$ juta ton Gabah Kering Giling (GKG) sehingga perkiraan akan menghasilkan sekam padi sekitar 20\% dari berat padi yang dihasilkan [1]. Selain itu, sekam padi mengandung silika cukup tinggi, yakni $16-20 \%$ berat dari sekam padi [2-4] dan diperoleh dengan cara yang sederhana, yaitu ekstraksi alkalis [5-7]. Silika yang diperoleh dari sekam padi juga mempunyai fasa amorf [8-11] dan mempunyai struktur orto silikat [12] yang sama dengan silikat yang terdapat dalam senyawa alkoksida logam transisi dan silikon alkoksida seperti Tetraethyl Ortosilicate sebagai bahan baku Mesoporous Silica [13-19] yang harganya mahal.

Mesoporous Silica merupakan salah satu jenis bahan berpori yang memiliki susunan pori-pori silindris berukuran seragam dengan diameter 2-50 nm, luas permukaan besar (700-1500 $\left.\mathrm{m}^{2} \mathrm{~g}^{-1}\right)$, volume pori besar (1 $\mathrm{cm}^{3} \mathrm{~g}^{-1}$ ), stabilitas termal yang baik dan fungsionalisasi permukaan yang mudah [20]. Mesoporous Silica menarik perhatian para ilmuwan pada era industrialisasi karena dapat digunakan sebagai catalyst, sensor, adsorption, chromatography [21], drug delivery [22,23], dan smart inhibitor corrosion [13-19,24].

Oleh karena itu, penelitian ini dilakukan sebagai pengembangan pemanfaatan silika sekam padi sebagai bahan baku pembuatan Mesoporous Silica untuk melihat gugus fungsi yang terbentuk dengan karakterisasi FTIR.

\section{METODE PENELITIAN}

\section{Ekstraksi Silika Sekam Padi}

Ekstraksi silika sekam padi diperoleh dengan metode alkalis [25]. 50 gram sekam padi yang telah dipreparasi ditambahkan ke dalam $500 \mathrm{ml}$ larutan $\mathrm{NaOH} \quad 1,5 \%$ dan dipanaskan hingga mendidih sambil diaduk. Sol silika yang diperoleh kemudian didinginkan, dan ditutup menggunakan plastik wrap selama 24 jam. Sol silika disaring menggunakan mesh untuk memisahkan sol silika dengan zat pengotor dan ampas filtrat silica.

Ekstrak sol kemudian ditambahkan dengan larutan $\mathrm{HNO}_{3} \quad 10 \%$ secara perlahanlahan sambil diaduk hingga terbentuk gel dengan $\mathrm{pH} \pm 7$. Gel silika yang diperoleh didiamkan selama 24 jam agar terjadi proses aging. Kemudian gel silika dicuci sampai bersih menggunakan aquades yang telah dipanaskan dan dikeringkan pada suhu $110^{\circ} \mathrm{C}$ selama 3 jam untuk memperoleh silika padatan.

\section{Ektraksi Natrium Silikat}

Natrium silikat $\left(\mathrm{Na}_{2} \mathrm{SiO}_{3}\right)$ diekstraksi dengan mencampurkan 6 gr serbuk silica sekam padi dengan $\mathrm{NaOH} 2 \mathrm{M}$ dalam $100 \mathrm{ml}$ akuades diaduk menggunakan magnetic stirrer dengan kecepatan putaran 500 rpm pada suhu $90^{\circ}$ sampai larut selama 2 jam. Sampel didinginkan dan ditambahkan $\mathrm{HNO}_{3}$ $2 \mathrm{M}$ diaduk sampai terbentuk gel dengan $\mathrm{pH}$ 7 kemudian didiamkan untuk proses aging. 
Gel dicuci menggunakan akuades yang telah dipanaskan, dikeringkan pada suhu $110^{\circ}$ selama 2 jam dan digerus untuk mendapatkan serbuk natrium silikat.

\section{Sintesis Mesoporous Silica}

Mesoporous Silica disintesis dengan melarutkan Cetyltrimethylammonium Bromide dengan variasi konsentrasi 2.0, $2.5 \%, 3.0 \%, 3.5 \%$ dalam $50 \mathrm{ml}$ akuades selama 30 menit. Larutan natrium silikat dicampurkan secara perlahan dalam larutan CTAB sampai homogen. Selanjutnya dititrasi dengan $\mathrm{HCl} 3 \mathrm{M}$ hingga membentuk gel pada pH 10 dan aging selama 24 jam.

Perlakuan hidrotermal dengan variasi suhu $120,130,145$, dan $160^{\circ} \mathrm{C}$ dilakukan selama 1 jam dalam autoclave. Endapan yang terbentuk kemudian difiltrasi dan dikeringkan pada suhu $100^{\circ} \mathrm{C}$ selama 2 jam hingga kering selanjutnya digerus menggunakan mortar pestle untuk kemudian dikarakterisasi FTIR.

\section{HASIL DAN PEMBAHASAN}

Hasil silika sekam padi, natrium silikat dan Mesoporous Silica ditunjukkan pada Gambar 1, sedangkan hasil FTIR natrium silikat dengan alat Spectrometer (Nicolet iS10) yang dilakukan di Laboratorium Terpadu dan Sentra Inovasi Teknologi (UPTLTSIT) ditunjukkan pada Gambar 2.

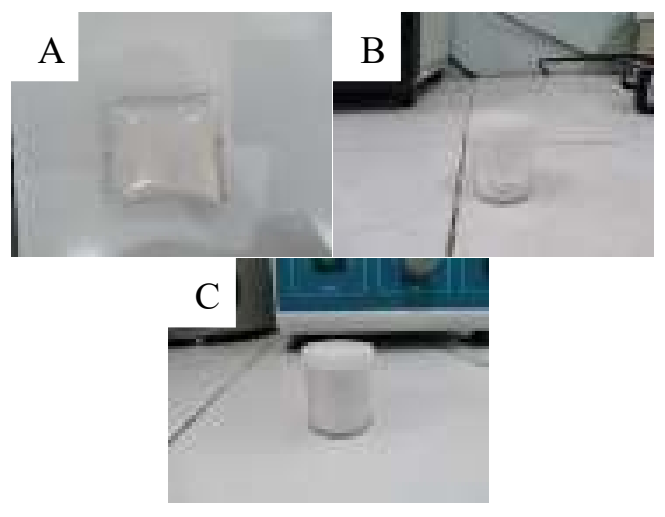

Gambar 1. (A) Silika sekam padi, (B) Natrium silikat, (C) mesoporous silica

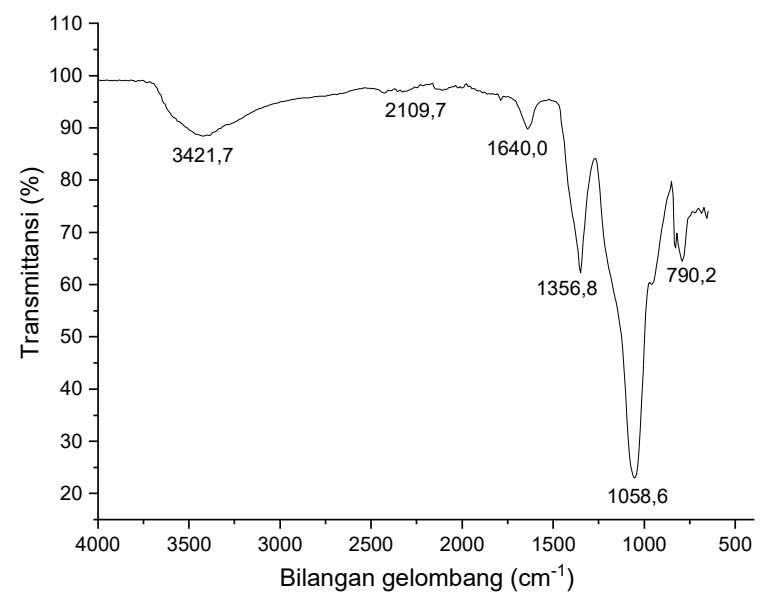

Gambar 2. Grafik FTIR Natrium Silikat

Berdasarkan Gambar 2 terlihat bahwa pada grafik terdapat puncak gelombang $3421,7 \mathrm{~cm}^{-}$ 1 yang mengindikasikan adanya vibrasi ulur asimetris $\mathrm{O}-\mathrm{H}$ dari $\mathrm{Si}-\mathrm{OH}$ [24], pada bilangan gelombang $2109,7 \mathrm{~cm}^{-1}$ menunjukkan adanya vibrasi ulur-H [26], pada bilangan gelombang $1640,0 \mathrm{~cm}^{-1}$ menunjukkan adanya vibrasi tekuk gugus $\mathrm{O}-\mathrm{H}$, pada bilangan gelombang $1356,8 \mathrm{~cm}^{-1}$ menunjukkan adanya gugus $\mathrm{C}-\mathrm{H}$, pada bilangan gelombang 1058,6 $\mathrm{cm}^{-1}$ menunjukkan adanya vibrasi ulur asimetris Si-O-Si dan pada bilangan 790,2 $\mathrm{cm}^{-1}$ menunjukkan adanya vibrasi ulur simetris SiO-Si [27].

\section{Hasil FTIR Dengan Variasi Suhu Hidrotermal}

Hasil analisis FTIR Mesoporous Silica dengan variasi suhu hidrotermal ditunjukkan pada Gambar 3. Pada grafik terdapat puncak gelombang $3242,8 \mathrm{~cm}^{-1}, 3362,1 \mathrm{~cm}^{-1}, 3384,4$ $\mathrm{cm}^{-1}$, dan $3399,3 \mathrm{~cm}^{-1}$ yang mengindikasikan adanya peregangan $-\mathrm{OH}$ dari $\mathrm{Si}-\mathrm{OH}$ atau silanol dari molekul air yang teradsorpsi pada permukaan silika. Getaran lentur molekul air yang terperangkap dalam matriks silika terdeteksi sebagai puncak pada bilangan gelombang $1640 \mathrm{~cm}^{-1}$, pita ini tidak dapat sepenuhnya hilang, namun itensitasnya dapat menurun karena adanya pemanasan.

Puncak serapan pada bilangan gelombang 2855,1 $\mathrm{cm}^{-1}$ dan 2922,2 $\mathrm{cm}^{-1}$ mengindikasikan vibrasi tekuk gugus fungsi 
O-H yang memperlihatkan adanya molekul air di dalam sampel. Sedangkan pada vibrasi bilangan gelombang $2124,6 \mathrm{~cm}^{-1}$ dan 2146,9 $\mathrm{cm}^{-1}$ merupakan virasi ulur dari ikatan hidrogen [26]. Bilangan gelombang 1461,1 $\mathrm{cm}^{-1}$ dan 1468,6 $\mathrm{cm}^{-1}$ dikaitkan dengan getaran asimetris dan simetris dari gugus $\mathrm{CH}_{3}$ dan $\mathrm{CH}_{2}$ [28].

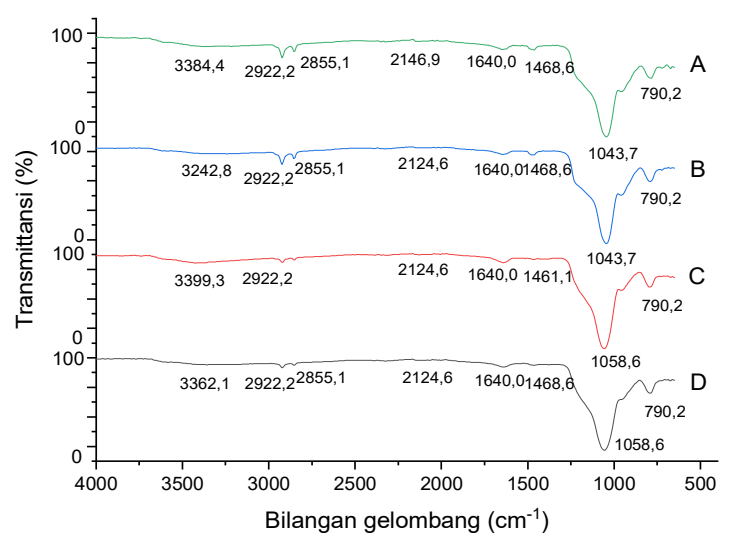

Gambar 3. Grafik FTIR silika mesopori (A) $120^{\circ} \mathrm{C}$, (B) $130^{\circ} \mathrm{C},(\mathrm{C}) 145^{\circ} \mathrm{C}$, dan (D) $160^{\circ} \mathrm{C}$.

Pita serapan kuat terdapat pada bilangan gelombang $1043,7 \mathrm{~cm}^{-1}$ dan $1058,6 \mathrm{~cm}^{-1}$ yang menunjukkan vibrasi ulur asimetris dari Si-OSi dan pada bilangan gelombang 790,2 $\mathrm{cm}^{-1}$ menunjukkan vibrasi ulur simetris dari Si-OSi [27].

\section{Hasil FTIR Dengan Variasi Konsentrasi Cetyltrimethylammonium Bromide}

Hasil analisis FTIR Mesoporous Silica dengan variasi konsentrasi Cetyltrimethylammonium Bromide ditunjukkan pada Gambar 4. Pada grafik terdapat puncak dengan bilangan gelombang $3384,4 \mathrm{~cm}^{-1}$, $3347,1 \mathrm{~cm}^{-1}$ dan $3377,0 \mathrm{~cm}^{-1}$ yang mengindikasikan adanya vibrasi ulur asimetris $\mathrm{O}-\mathrm{H}$ yang terjadi akibat adanya ikatan antara atom hidrogen dengan gugus silanol Si-OH [24]. Pada bilangan gelombang $2922,2 \mathrm{~cm}^{-1}$ dan $1640,0 \mathrm{~cm}^{-1}$ menunjukkan vibrasi tekuk dari gugus $\mathrm{OH}$. Pada bilangan gelombang 2132,0 $\mathrm{cm}^{-1}, 2124,6 \mathrm{~cm}^{-1}$ dan $2117,1 \mathrm{~cm}^{-1}$ menunjukkan vibrasi ulur dari ikatan hidrogen [26]. Pada bilangan gelombang $1468,6 \mathrm{~cm}^{-1}$ menunjukkan adanya vibrasi tekuk dari gugus $\mathrm{C}-\mathrm{H}$. Pada bilangan gelombang 1043,7 $\mathrm{cm}^{-1}, 1051,1 \mathrm{~cm}^{-1}, 1058,6$ $\mathrm{cm}^{-1}$ dan 1043,7 $\mathrm{cm}^{-1}$ menunjukkan adanya vibrasi ulur asimetris dari gugus Si-O-Si. Pada bilangan gelombang 790,2 $\mathrm{cm}^{-1}$ menunjukkan adanya vibrasi ulur simetris gugus Si-O-Si [27].

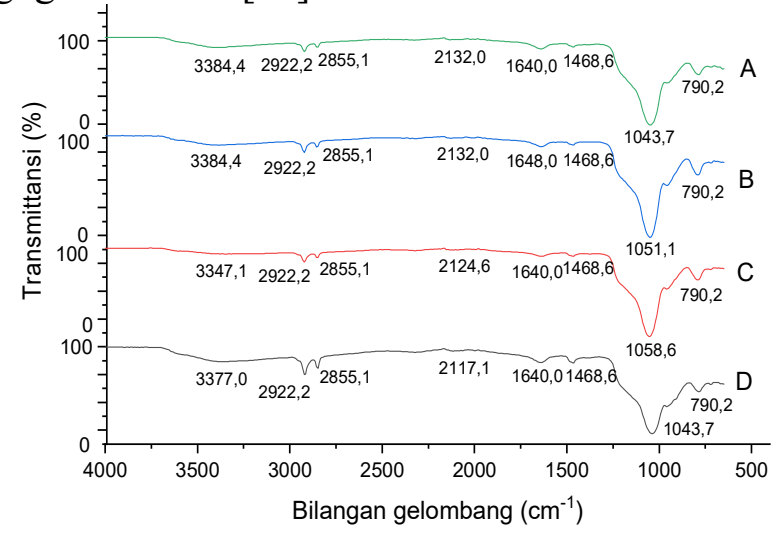

Gambar 4. Grafik FTIR silika mesopori (A) $2 \%$, (B) $2,5 \%$, (C) $3 \%$, dan (D) 3,5\%

\section{KESIMPULAN}

Berdasarkan penelitian yang telah dilakukan dapat disimpulkan bahwa gugus fungsi yang paling dominan pada silika berbasis sekam padi dengan variasi suhu \& konsentrasi

Cetyl-trimethylammonium Bromide adalah Si-O-Si. Sementara, gugus lainnya adalah $\mathrm{C}-\mathrm{H},-\mathrm{H}, \mathrm{O}-\mathrm{H}$ dan $-\mathrm{OH}$. Berdasarkan gugus fungsi tersebut, maka silika berbasis sekam padi dapat digunakan sebagai bahan baku Mesoporous Silica.

\section{DAFTAR PUSTAKA}

[1] BPS Propinsi Lampung, Perkembangan Indikator Makro Sosial Ekonomi Provinsi Lampung Triwulan III, Bandar Lampung: CV Jaya Wijaya, 2019.

[2] V.B. Carmona, R.M. Oliveira, W.T.L. Silva, L.H.C. Mattoso, and J.M. 
Marconcini, "Nanosilica from rice husk: extraction and characterization," Industry Crops and Production, 43, pp. 291-296, 2013.

[3] S. Kumar, P. Sangwan, M.V.R. Dhankhar, S. Bidra, (2013), "Utilization of rice husk and their ash: a review," Journal of Chemistry Environmental Science, 1, pp. 126129, 2013.

[4] S. Azat, A.V. Korobeinyk, K. Moustakas, V.J. Inglezakis, "Sustainable production of pure silica from rice husk waste in Kazakhstan," Journal of Cleaner Production., 217, pp. 352-359, 2019.

[5] E. Rafieel, S. Shahebrahimi, M. Feyzil, and M. Shaterzadeh, "Optimization of synthesis and characterization of nanosilica produced from rice husk (a common waste material)," International Nano Letters, 2, pp. 1-8, 2012.

[6] B.I. Ugheoke, and O.A. Mamat, "A Novel method for high volume production of nano silica from rice husk: process development and product characteristics," International Material Enggineering Innovation, 3, pp. 139-155, 2012.

[7] L.N.A. Tuan, L.T.K. Dung, L.D.T. Ha, N.Q. Hien, D.V. Phu, B.D. Du, "Preparation and characterization of nanosilica from rice husk ash by chemical treatment combined with calcination," Vietnam Journal of Chemistry, 55, pp. 446-455, 2017.

[8] W. Khopthong, and B. Cherdhirunkorn, "Production of silicabased ceramics sintered under nitrogen atmosphere from rice husk and sugarcane bagasse ash," Journal of Metals, Materials and Minerals, 30 (2), pp. 76-82, 2020.

[9] W. Simanjuntak, S. Sembiring, K.D. Pandiangan, F. Syani, R. Situmeang, "The use of liquid smoke as a substitute for nitric acid of amorphous silica from rice husk through sol-gel route,"
Oriental Journal of Chemistry, 32 (4), pp. 2079-2085, 2015.

[10] S. Sembiring, "Karakterisasi silika sekam padi sebagai bahan keramik dengan teknik sintering," Prosiding, Dies Natalis Universitas Lampung, pp. 123-128, 2007.

[11] S. Sembiring, dan P. Karo-Karo, "Pengaruh suhu sintering terhadap karakteristik termal dan mikrostruktur silika sekam padi," Jurnal Sains dan Teknologi, Mipa Unila, 13. (3), pp. 233-239, 2007.

[12] A. Mehta, and R.P. Ugwekar, "Extraction of silica and other related products from rice husk," International Enggineering Research and Application, 25, pp. 43-48, 2015.

[13] D. G. Borisova, D. Mohwald, H., And Shchukin, .Mesoporous Silika Nanoparticles For Active Corrosion Particles," ACS Nano, vol. 5, no. 3, pp. 1939-1946, 2011.

[14] M. Saremi dan A. K. Yeganeh, "Pengaruh penambahan Inhibitor Silika Mesopori pada Pelapisan Korosi," J. Ultrafine Grained Bahan Berstruktur Nano, vol. 46, no. 1, pp. 11-17, 2013.

[15] I. V. Falcón, J.M. Otubo, L.M. Aoki, "Highly Ordered Mesoporous Silika Loaded With Dodecylamine For Smart Anticorrosion Coatings," Surf. Coat. Technol., pp. 1-11, 2015.

[16] C. Zea, R. Barranco-Garcı'a, J. Alca' ntara, B. Chico, M. Morcillo, D. de la Fuente, "Hollow Mesoporous Silica Nanoparticles Loaded With Phosphomolybdate As Smart Anticorrosive Pigment," J. Coat. Technol. Res., 2017.

[17] Changjean, Wen-Chyuan, Huang, L. Tseng, "Repairable Mesoporus Silika Film With Replenishing Corrosion Inhibitor As Corrosion Protection Layer Of Aluminum Alloy," Elsevier, 192, pp. 82-88, 2014.

[18] I. Recloux, M. Mouanga, M. E. Druart,Y. Paint, M. G. Olivier, "Silica 
Mesoporous Thin Films as Containers for Benzotriazole for Corrosion Protection of 2024 Aluminium Alloys," Appl. Surf. Sci, (346), pp. 124133, 2015.

[19] M. F. Rahsepar, H. Mohebbi, Hayatdavoudi, "Synthesis And Characterization Of Inhibitor-Loaded Silica Nanospheres For Active Corrosion Protection Of Carbon Steel Substrate," Journal of Alloys and Compounds, 2017.

[20] A. Walcarius, "Mesoporous Materials And Electrochemistry," Chem. Soc. Rev., vol. 42, no. 09, pp. 4098, 2013.

[21] G. Kalies, R. Rockmann, D. Tuma, J. Gapke, "Applied Surface Science," 256, pp. 5395, 2010.

[22] I. I. Slowing, B. G. Trewyn, S. Giri, V. S.-Y. Lin, "Mesoporous Silica Nanoparticles for Drug Delivery and Biosensing Applications," Advance Functional Material, pp. 1225-1236, 2007.

[23] P. Yang, S. Gai, J. Lin, "Functionalized mesoporous silica materials for controlled drug delivery," Chem. Soc. Rev., 41, pp. 3679-3698, 2012.

[24] H. Keyvani, A., Yeganeh, M., Rezaeyan, "Application Of Mesoporous Silika Nanocontainers As
An Intelligent Of Molybdate Corrosion Inhibitor Embedeed In The Epoxy Coated Steel," Prog. Nat. Sci. Mater. Int., 2017.

[25] E. Suka, I. G., Simanjuntak, W., Sembiring, S., dan Trisnawati, "Karakteristik Silika Sekam Padi Dari Provinsi Lampung Yang Diperoleh Dengan Metode Ekstraksi," MIPA, vol. 37, no. 1, pp. 47-52, 2008.

[26] R. D. Suprihatin, Setiawan, F. A., Cahya, "Adsorben Komposite Silica Dari Limbah Abu Sekam Padi," J. Tek. Kim., vol. 13, no. 2, 2019.

[27] D. Purwaningsih, H., Pratiwi, V. M., Purwana, S. A. B., Nurdiansyah, H., Rahmawati, Y., and Susanti, "Fabricatiom of Mesoporus Silica Nanoparticles by Solgel Method Followed Various Hydrothermal Temperature," ICOMMET. AIP Conf. Proc, vol. 1945, 2018.

[28] M. Ghorbani, F., Younesi, H., Mehraban, Z., Sabri Celik, M., Ghoreyshi, A. A., Anbia, "Aqueous Cadmium Ions Removal by Adsorption on APTMS Grafted Mesopori Silica MCM-41 in Batch and Fixed Bed Column Processes," Int. J. Eng, vol. 26, pp. 473-488, 2013. 